Article

\title{
Impedance Matching Method for 6.78 MHz Class-E2-Based WPT System
}

\author{
Yi Zhang, Yue Feng, Sheng Liu, Jiande $W u *$ and Xiangning He \\ College of Electrical Engineering, Zhejiang University, Hangzhou 310027, China; zhangyiee@zju.edu.cn (Y.Z.); \\ yuef@zju.edu.cn (Y.F.); sheng_liu@zju.edu.cn (S.L.); hxn@zju.edu.cn (X.H.) \\ * Correspondence: eewjd@zju.edu.cn; Tel.: +86-1360-051-1674
}

check for

updates

Citation: Zhang, Y.; Feng, Y.; Liu, S.; $\mathrm{Wu}, \mathrm{J} . ; \mathrm{He}, \mathrm{X}$. Impedance Matching Method for 6.78 MHz Class-E2-Based WPT System. Energies 2021, 14, 4289. https://doi.org/10.3390/en14144289

Academic Editor: Dong-Wook Seo

Received: 6 June 2021

Accepted: 12 July 2021

Published: 15 July 2021

Publisher's Note: MDPI stays neutral with regard to jurisdictional claims in published maps and institutional affiliations.

Copyright: (c) 2021 by the authors. Licensee MDPI, Basel, Switzerland. This article is an open access article distributed under the terms and conditions of the Creative Commons Attribution (CC BY) license (https:// creativecommons.org/licenses/by/ $4.0 /)$.

\begin{abstract}
The performance of a conventional Class-E2-based WPT system is sensitive to system parameters such as the coil coupling coefficient and load variation. System efficiency decreases rapidly when the coil coupling coefficient and load deviate from their optimum values. In this paper, an impedance matching method and a design procedure are proposed to maintain high system efficiency over a wider range of coupling coefficient and load variations. The load-pull technique is adopted to identify the high-efficiency load region of a Class-E power amplifier (PA), and a double-Ltype impedance matching network (IMN) is proposed to transform the load impedance of a Class-E PA into a high-efficiency working region. Compared to a single L-type IMN, a double-L-type IMN is more flexible and has better tuning performance. A $6.78 \mathrm{MHz}$ Class-E2-based WPT system was built to validate the proposed design method. The experimental results show that the proposed double-L-type IMN can significantly attenuate the decline in Class-E PA efficiency when system parameters dynamically change. With a double-L-type IMN, the WPT system could maintain high efficiency (over 55\%) under a wider range of coil coupling coefficient and load variations. The peak system efficiency reached $83.2 \%$ with $13.7 \mathrm{~W}$ output power. The impedance matching method and design procedure in this paper could provide a practical solution for building a high-efficiency WPT system with strong robustness.
\end{abstract}

Keywords: impedance matching method; double-L-type IMN; class-E2-based WPT system

\section{Introduction}

In recent years, inductive wireless power transfer systems have been widely used in mobile devices, such as cell-phones, smart watches, and earphones. To improve the user experience, medium-range wireless power transfer (WPT) and multiple device charging technologies have attracted considerable attention from both academia and industry. It will be promising for consumer electronics to achieve longer transmission distances in WPT systems by increasing the system frequency to megahertz. Furthermore, compared to kilohertz WPT systems, megahertz WPT systems will be more compact, which is advantageous when charging multiple devices simultaneously [1-4]. Higher-frequency WPT technologies, i.e., gigahertz WPT technologies, are being developed for use in nanoscale and ultra-low-power systems for biomedical applications, wireless sensors, and microwave detection, which require far less power than the mobile devices mentioned above [5-7]. Therefore, megahertz WPT systems are discussed in this paper. However, conventional hard-switching inverters and rectifiers, such as full-bridge inverters and rectifiers, suffer from large switching losses and harmonics when applied in megahertz WPT system [8]. For a megahertz WPT system, a soft-switching-based Class-E2 DC-DC converter composed of a Class-E power amplifier (PA) and a Class-E rectifier is appropriate [9].

The well-designed Class-E PA and rectifier are operated in zero-voltage-switching (ZVS) and zero-voltage-derivative-switching (ZDS) modes, achieving higher efficiency than hard-switching topologies [10]. However, the design method for a Class-E PA is only 
valid under a fixed load. The performance of a Class-E PA deteriorates rapidly when its load impedance deviates from the optimum value [11]. In practice, the problem is that the load impedance of a Class-E PA is dynamically changed with uncertainties such as coil misalignment and load variation in multiple device charging, which lead to a decline of efficiency $[12,13]$. In terms of rectifiers, a soft-switching Class-E rectifier is employed in the Class-E2-based WPT system. When operated in a megahertz system, a soft-switching Class-E rectifier has smaller switching losses and harmonics content than hard-switching rectifiers [14]. To achieve better performance, the parameters of a Class-E rectifier need to be carefully designed with DC load variation [15].

Various adaptive methods, such as adaptive frequency regulation, adaptive load regulation, and adaptive impedance matching, have been developed to improve the performance of a WPT system with dynamically changing coil distances and loads. In [12,16], adaptive frequency tuning approaches were used to optimize the resonant frequency for minimum reflections. However, the frequency can be operated outside of the allowed bandwidth (e.g., the narrow $6.78 \mathrm{MHz}$ or $13.56 \mathrm{MHz}$ ISM band). In [17], a nonlinear paritytime (PT) symmetric circuit with an oscillation frequency that can automatically adapt to the changing coupling coefficient was proposed. It has been experimentally verified that nonlinear a PT symmetric circuit can maintain high efficiency despite variations in transfer distance. The adaptive load regulation method was adopted in [18]; it added a dc-dc converter (e.g., buck converter) after the rectifier, whose equivalent input impedance could be changed with the duty cycle. To optimize the load impedance seen by the rectifier, a tracking algorithm is required. Adaptive impedance matching is a practical method to optimize system performance [19,20]. In [19], a capacitor matrix was proposed to track the optimum impedance-matching point in the cases of different coil distances. A tunable L-type IMN was adopted for impedance matching in [20]. The impedance tuning methods proposed in $[19,20]$ experimentally verified that the performance of a Class-E PA is improved for a wider-range load. However, all of the adaptive tuning methods mentioned above require additional detection circuits, control circuits, and tuning algorithms, thus inevitably increasing system complexity. Based on the foregoing considerations, a simplified method, namely, static impedance matching, is preferred to be used with its simple structure and reliability. Only fixed components are used in the static impedance matching method.

To improve the performance of a Class-E PA, the load-pull technique was adopted to identify the high-efficiency working region of a Class-E PA. A fixed double-L-type IMN is proposed in this paper to transform load impedance into a high-efficiency working region. Compared to a single L-type IMN, a double-L-type IMN has the advantage of more flexibility in the design process for fine tuning. Furthermore, in order to achieve high system efficiency, high-Q inductors are employed in the Class-E2-based WPT system, which can reduce power losses.

The main contributions of this paper are as follows.

1. A novel double-L-type IMN is proposed in the design of a Class-E2-based WPT system. System efficiency is significantly improved over a much wider range of coupling coefficient and load variations.

2. A practical design procedure for building a high-efficiency WPT system with strong robustness is developed in this paper.

This paper is organized as follows. Section 2 analyzes conventional Class-E2-based WPT systems. The equivalent load impedance of a Class-E PA in a WPT system is derived and analytical expressions of efficiency are also presented. Section 3 discusses the proposed impedance matching method. The L-type IMN is designed to obtain optimized load impedance under a fixed coil distance and load. The load-pull technique is adopted to identify the high-efficiency load impedance region of a Class-E PA. For better tuning performance, a double-L-type IMN is proposed for finer impedance transformation. Then a design procedure is developed to calculate the parameters of the double-L-type IMN. The simulation results of Class-E2-based WPT systems with/without double-L-type IMN 
are compared. In Section 4, the proposed design method is validated by experiments. In Section 5, the conclusions are given.

\section{Analysis of a Conventional Class-E2-based WPT System}

Figure 1 shows the basic topology of a conventional Class-E2-based WPT system, which consists of a Class-E PA, two coupling coils, and a Class-E rectifier. In this circuit model, $L_{\mathrm{RFC}}, L_{\mathrm{r}}, L_{\mathrm{TX}}, L_{\mathrm{RX}}, C_{\mathrm{f}}$, and $L_{\mathrm{f}}$ are constant values and $C_{\mathrm{p}}, C_{\mathrm{r}}, C_{\mathrm{TX}}, C_{\mathrm{RX}}$, and $C_{\mathrm{D}}$ are the designed parameters according to the constant circuit parameters above. $Z_{\mathrm{tx}}$ and $Z_{\text {rec }}$ are the equivalent input impedance of coupling coils and a Class-E rectifier, respectively. In this section, Class-E PA and rectifiers are designed under fixed coil distance and DC load. With carefully designed parameters, both the Class-E PA and rectifier can be operated in ZVS and ZDS modes, allowing the Class-E2-based WPT system to achieve high efficiency.

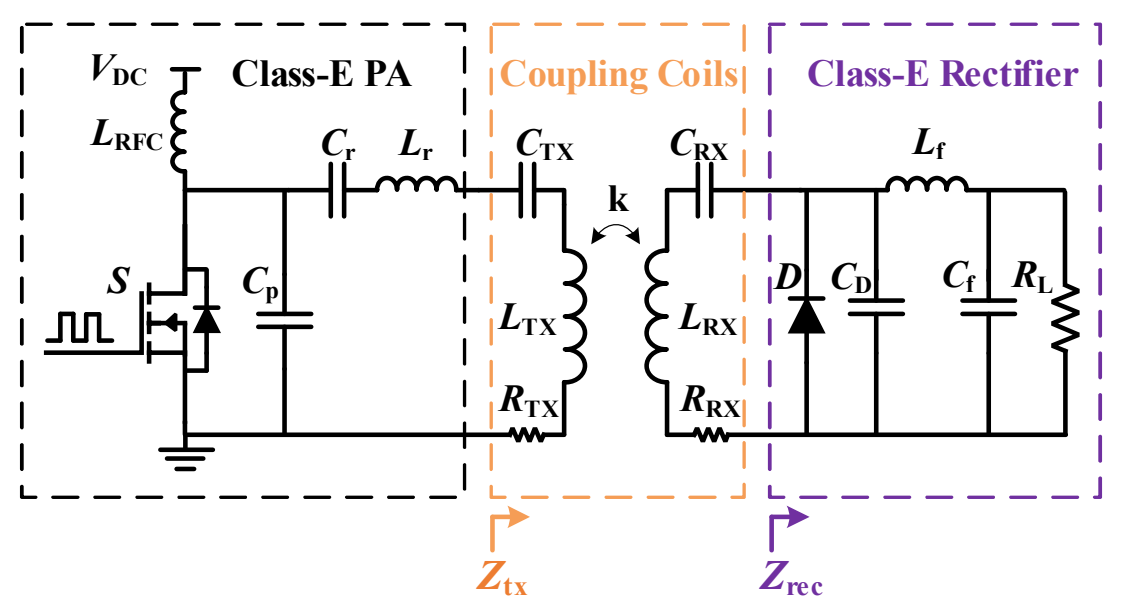

Figure 1. Circuit model of a conventional Class-E2-based WPT system.

\subsection{Design Procedure for Conventional Class-E PA}

As shown in Figure 1, a typical Class E PA consists of a DC power supply $V_{\mathrm{DC}}$, a choke inductor $L_{\mathrm{RFC}}$, a parallel capacitor $C_{\mathrm{p}}$, a switch $S$, a resonant capacitor $C_{\mathrm{r}}$, a resonant inductor $L_{r}$, and load. The RF choke inductor $L_{\text {RFC }}$ is large enough so that the current through it is constant. The GaN switch output capacitor is included in the parallel capacitor $C_{\mathrm{p}}$. Moreover, the switch $S$ is regarded as ideal. In a Class-E2-based WPT system, the equivalent load impedance of Class-E PA is $Z_{t x}$. In order to minimize switching losses, the switch of the Class-E PA needs to satisfy ZVS and ZDS conditions. Normally, the switch in a Class-E PA is designed to be operated with a 50\% duty cycle. The following equations are derived when the duty cycle of the switch is $50 \%$. To achieve soft-switching, the designed parameters of the Class-E PA, $C_{p}$ and $C_{r}$ are required to satisfy [21]

$$
C_{-} \mathrm{p}=8 /\left(\pi\left(\pi^{2}+4\right) \omega R_{-} \mathrm{tx}\right)
$$

and

$$
C \_r=8 /\left(\pi(\pi 2+4) \omega R \_t x\right)
$$

where $R_{t x}$ is the real component of equivalent load impedance $Z_{t x}$.

$L_{\mathrm{r}}-C_{\mathrm{r}}-R_{\mathrm{tx}}$ is a series resonant circuit, whose quality factor $\left(Q_{\mathrm{LCR}}\right)$ is the key to achieve close-to-sinusoidal input current of the transmitting coil. $Q_{\mathrm{LCR}}$ is expressed as

$$
Q \_\mathrm{LCZ}=\left(\omega L \_\mathrm{r}\right) / R \_\mathrm{tx}
$$

High $Q_{\text {LCR }}$ helps to reduce the harmonic content of the coil current, which is beneficial to realizing high system efficiency. The value of $Q_{\mathrm{LCR}}$ is always set to be larger than 10 . 


\subsection{Coupling Coils and Class-E Rectifier}

As shown in Figure 2, a Class-E rectifier is composed of a diode $D$, a shunt capacitor $C_{\mathrm{D}}$, a low pass filter $L_{\mathrm{f}}-C_{\mathrm{f}}$, and a DC load $R_{\mathrm{L}}$. Diode $D$ is employed as the switching device of the Class-E rectifier. The diode is operated in half-wave rectified mode. When the diode is turned off, both the voltage $V_{\mathrm{D}}$ and its derivative $d V_{\mathrm{D}} / d t$ are zero, realizing a soft-switching condition, which corresponds to the ZVS and ZDS state of the Class-E PA. Therefore, the Class-E rectifier can realize high-efficiency rectification at high frequency. Different from Class-E PAs, Class-E rectifiers are always capable of implementing ZVS and ZDS switching at arbitrary parameters with a different duty cycle.

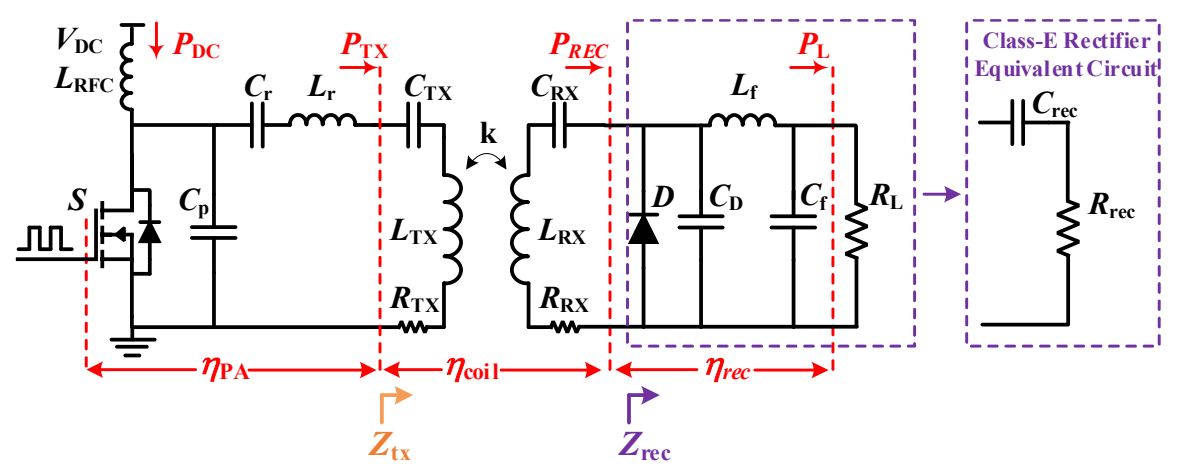

Figure 2. Equivalent circuit of Class-E rectifier.

The Class-E rectifier is the post-stage circuit of a WPT system. The input current of the rectifier is also the output of the receiving coil, which can be considered as a sine wave. In the circuit model of the Class-E rectifier, it can be represented as a current source. When analyzing the Class-E rectifier circuit, it is assumed that:

- The rectified diode is an ideal diode, whose on-conduction voltage drop and reverse recovery are zero;

- The filter inductor is large enough and the current ripple flowing through $L_{\mathrm{f}}-C_{\mathrm{f}}$ low pass filter is negligible;

- The input of rectifier is considered to be an ideal current source.

When the above conditions are satisfied, the diode shunt capacitor $C_{\mathrm{D}}$ is a function of the DC load $R_{\mathrm{L}}$ and the diode duty cycle $D_{\mathrm{d}}$. It can be derived as

$$
\begin{array}{r}
C_{\mathrm{D}}=\frac{1}{2 \pi w R_{\mathrm{L}}}\left\{1-\cos \left(2 \pi D_{\mathrm{d}}\right)-2 \pi^{2}\left(1-D_{\mathrm{d}}\right)^{2}\right. \\
\left.+\frac{\left[2 \pi\left(1-D_{\mathrm{d}}\right)+\sin \left(2 \pi D_{\mathrm{d}}\right)\right]^{2}}{1-\cos \left(2 \pi D_{\mathrm{d}}\right)}\right\}
\end{array}
$$

where duty cycle $D_{\mathrm{d}}$ is designed to be $50 \%$.

As shown in Figure 2, the input impedance of the Class-E rectifier is equivalent to a capacitor $C_{\text {rec }}$ and a resistor $R_{\text {rec }}$ in series [22]. $C_{\text {rec }}$ and $R_{\text {rec }}$ are derived as

$$
\begin{aligned}
& C_{\text {rec }}=\pi C_{\mathrm{D}}\left[\pi\left(1-D_{\mathrm{d}}\right)+\sin \left(2 \pi D_{\mathrm{d}}\right)-\frac{1}{4} \sin \left(4 \pi D_{\mathrm{d}}\right) \cos \left(2 \phi_{\mathrm{d}}\right)-\frac{1}{2} \sin \left(2 \phi_{\mathrm{d}}\right) \sin ^{2}\left(2 \pi D_{\mathrm{d}}\right)\right. \\
& \left.-2 \pi\left(1-D_{\mathrm{d}}\right) \sin \phi_{\mathrm{d}} \sin \left(2 \pi D_{\mathrm{d}}-\phi_{\mathrm{d}}\right)\right]^{-1}
\end{aligned}
$$

and

$$
R_{\text {rec }}=2 R_{\mathrm{L}} \sin ^{2} \phi_{\mathrm{d}}
$$

respectively, where $\varnothing_{\mathrm{d}}$ is the phase shift of the input voltage and current of the Class-E rectifier. $\varnothing_{\mathrm{d}}$ can be expressed as

$$
\tan \phi_{\mathrm{d}}=\frac{1-\cos \left(2 \pi D_{\mathrm{d}}\right)}{2 \pi\left(1-D_{\mathrm{d}}\right)+\sin \left(2 \pi D_{\mathrm{d}}\right)}
$$

In Figure $2, C_{\mathrm{TX}}$ and $C_{\mathrm{RX}}$ are the resonant capacitors of the transmitting side and receiving side, respectively. $L_{\mathrm{TX}}$ and $L_{\mathrm{RX}}$ are the inductances of the transmitting coil and 
receiving coil, respectively. $R_{\mathrm{TX}}$ and $R_{\mathrm{RX}}$ are the equivalent resistances that represent the loss of the transmitting coil and receiving coil, respectively. $k$ is the coupling coefficient between the transmitting coil and receiving coil. Consider that the reactance of $Z_{\text {rec }}$ $C_{\mathrm{TX}}$, and $C_{R X}$ should be designed with the following equations to make the two coils exactly resonant:

$$
\begin{gathered}
j \omega L_{\mathrm{TX}}+\frac{1}{j \omega C_{\mathrm{TX}}}=0 \\
j \omega L_{\mathrm{RX}}+\frac{1}{j \omega C_{\mathrm{RX}}}+\frac{1}{j \omega C_{\mathrm{rec}}}=0
\end{gathered}
$$

where $\omega$ is the resonant frequency.

\subsection{System Efficiency Analysis}

As is shown in Figure $2, P_{\mathrm{DC}}, P_{\mathrm{TX}}, P_{\mathrm{REC}}$, and $P_{\mathrm{L}}$ are the input DC power, input power of the transmitting coil, input power of the rectifier, and output power of the load, respectively. $Z_{t x}$ and $Z_{\text {rec }}$ are the equivalent input impedances of the transmitting coil and Class-E rectifier, respectively. $\eta_{\mathrm{PA}}, \eta_{\text {coil }}$ and $\eta_{\text {rec }}$ are defined as

$$
\eta_{\text {coil }}=\frac{P_{\text {REC }}}{P_{\mathrm{TX}}}, \eta_{\text {rec }}=\frac{P_{\mathrm{L}}}{P_{\mathrm{REC}}}
$$

whose product is the system efficiency $\eta_{\text {sys }}$.

According to (8)-(9), the equivalent load impedance of the Class-E PA is a pure resistive load when both the transmitting side and receiving side are exactly resonant. The equivalent input impedance of the transmitting side is derived as

$$
\mathrm{Z}_{\mathrm{tx}}=R_{\mathrm{TX}}+\frac{(\omega M)^{2}}{R_{\mathrm{RX}}+R_{\mathrm{rec}}}
$$

where $M$ is the mutual inductance of two coils. $M$ can be expressed as

$$
M=k \sqrt{L_{\mathrm{TX}} L_{\mathrm{RX}}}
$$

Then efficiency of coupling coil link $\eta_{\text {coil }}$ can be derived as

$$
\eta_{\text {coil }}=\frac{(\omega M)^{2} R_{\text {rec }}}{\left[R_{\mathrm{TX}}\left(R_{\mathrm{rec}}+R_{\mathrm{RX}}\right)+(\omega M)^{2}\right]\left(R_{\mathrm{rec}}+R_{\mathrm{RX}}\right)}=\frac{k^{2} Q_{\mathrm{TX}} Q_{\mathrm{RX}}}{1+k^{2} Q_{\mathrm{TX}} Q_{\mathrm{RX}}} \frac{R_{\mathrm{rec}}}{R_{\mathrm{RX}}+R_{\mathrm{rec}}}
$$

where $Q_{\mathrm{TX}}$ and $Q_{\mathrm{RX}}$ are the quality factors of the transmitting coil and receiving coil, respectively. In order to improve $\eta_{\text {coil }}$, high-Q coils are employed, which are wound with $3 \mathrm{~mm}$ (diameter) copper wire for 2 turns. The $Q$ values of the coils are simulated with High Frequency Structure Simulator (HFSS) and the simulated Q values of the coils are 694.9 at $6.78 \mathrm{MHz}$. It can be observed from (13) that the efficiency of the coupling coil link $\eta_{\text {coil }}$ is not sensitive to coupling coefficient $\mathrm{k}$ when $\mathrm{Q}$ is very large.

The efficiencies of the Class-E PA, coupling coil link, Class-E rectifier, and overall system are simulated when coil distance D and DC load $R_{\mathrm{L}}$ vary. As shown in Figure 3, the efficiencies of the coupling coil link and rectifier remain high and have only a minor effect on overall system efficiency with variations in $\mathrm{D}$ and $R_{\mathrm{L}}$. However, the performance of the Class-E PA degrades due to the variations in $\mathrm{D}$ and $R_{\mathrm{L}}$. Thus, the key point to improve system efficiency is to develop a high-efficiency Class-E PA over a wide-range load variation. 


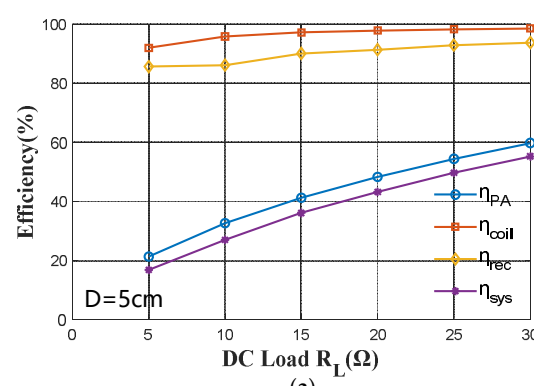

(a)

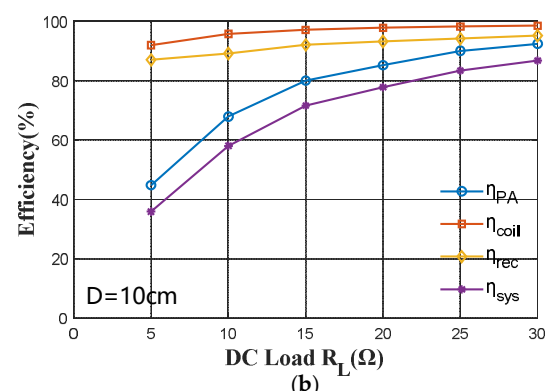

(b)

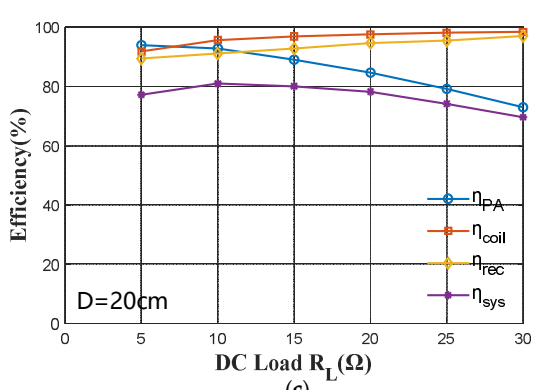

(c)

Figure 3. Efficiencies of Class-E PA, coupling coil link, Class-E Rectifier, and overall system with different coil distance D and DC load $R_{\mathrm{L}}:(\mathbf{a}) \mathrm{D}=5 \mathrm{~cm},(\mathbf{b}) \mathrm{D}=10 \mathrm{~cm},(\mathbf{c}) \mathrm{D}=20 \mathrm{~cm}$.

\section{Proposed Impedance Matching Method for Class-E2-Based WPT System}

The conventional design method can only guarantee that the system will work efficiently under a fixed coil coupling coefficient and load. However, the load impedance of a Class-E PA is dynamically changed with the uncertainties in real applications, such as coil misalignment and load variation.

Figure 4a shows a conventional Class-E PA with equivalent load impedance $Z_{\mathrm{tx}}$, which is also the input impedance seen by the coupling coils. To realize high efficiency, the key point is to transform the equivalent load impedance of the Class-E PA to a highefficiency working region. In this section, the design methodology is based on the load-pull technique and impedance matching technique. The load-pull technique is used to identify the high-efficiency load impedance region of the Class-E PA, which provides guidance for impedance matching. The impedance matching process is:

1. L-type IMN is employed for preliminary impedance transformation;

2. Load-pull technique is used to identify high-efficiency Class-E PA load impedance region;

3. Double-L-type IMN is used for finer impedance matching.

\subsection{The Design of an L-Type IMN}

An L-type IMN is employed for impedance matching under a fixed coupling coefficient and DC load. The L-type IMN is composed of only two components, thus its impedance matching capability is limited.

In this design case, the original equivalent load impedance of a Class-E PA is $50 \Omega$ (corresponding to $k=0.145, R_{\mathrm{L}}=10 \Omega$ ), which is consistent with the general power amplifier design. The optimum value of resistive load impedance of the Class-E PA is set to be $10 \Omega$. With the purpose of transforming the original load impedances to locate the high-efficiency point, an L-type IMN is added between the Class-E PA and the transmitting coil, which is shown in Figure $4 \mathrm{~b}$. To be specific, the objective of the L-type IMN is to transform the original load impedance $(50 \Omega)$ to the optimum value $(10 \Omega)$. The design procedure for the L-type IMN is very convenient and easy to accomplish with the help of smith chart tools in a radio frequency simulation software, Advanced Design System (ADS). In the smith chart, the impedance moves along the admittance circle when a shunt inductor or capacitor is added, and the impedance moves along the resistive circle when a series inductor or capacitor is added. Figure 5 demonstrates the process of impedance transformation using an L-type IMN. Note that all the impedances in this smith chart are nominalized with $50 \Omega$. 


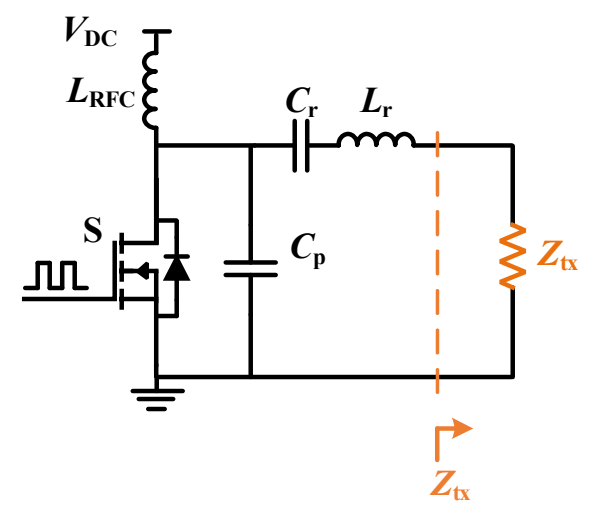

(a)

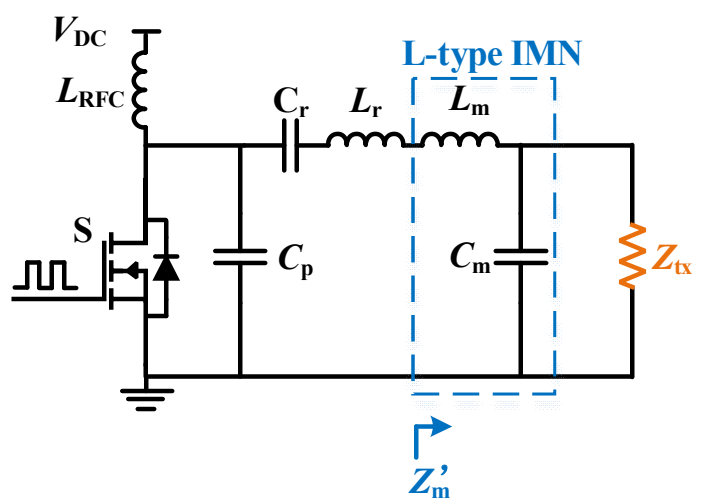

(b)

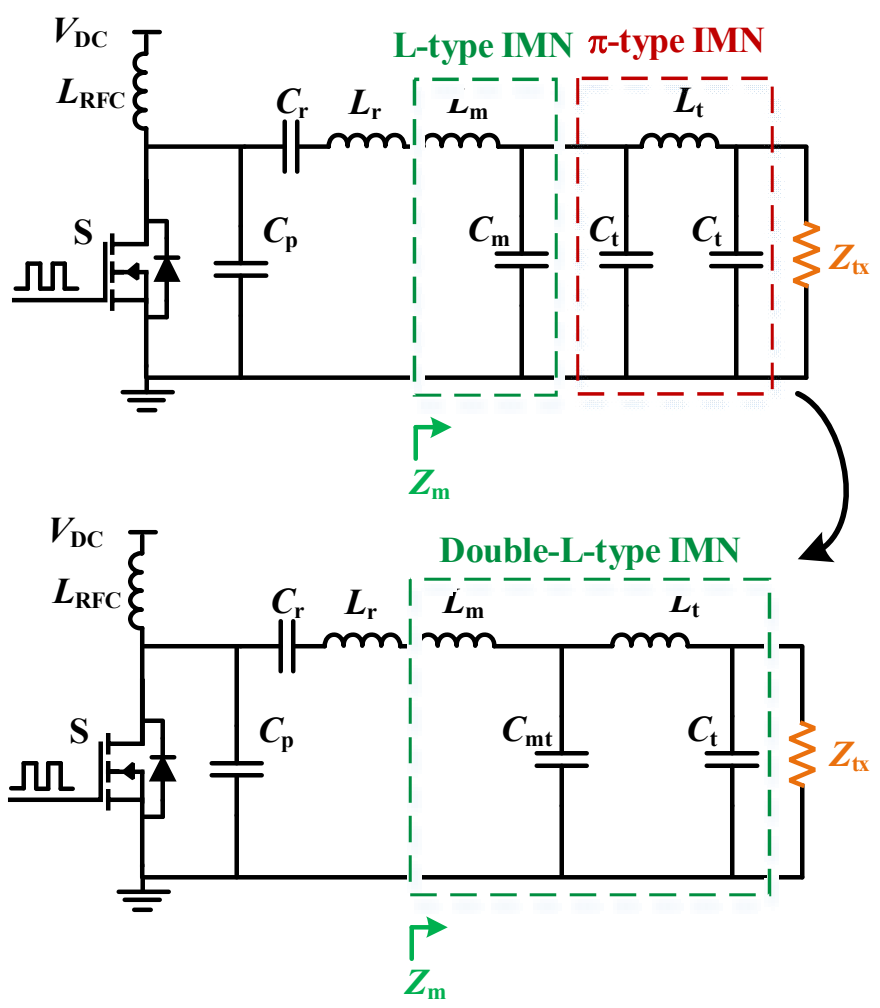

(c)

Figure 4. Class-E power amplifier circuit: (a) conventional Class-E PA; (b) Class-E PA with an L-type IMN; (c) Class-E PA with a double-L-type IMN.

\subsection{Load-Pull Technique and Doubel-L-Type IMN}

To evaluate the performance of a Class-E PA with an L-type IMN, the load-pull technique is employed. The load-pull technique can identify the high-efficiency load impedance region of a Class-E PA. A circuit model is built in ADS and the simulation results are shown in Figure 6. The smith chart illustrates the efficiency and output power contours when the load impedance of the Class-E PA varies. For clarity, the smith chart in Figure 6 is nominalized with $20 \Omega$. With an L-type IMN, the original resistive load impedance line $Z_{\mathrm{tx}}$, which ranges from 5 to $100 \Omega$, is transformed to impedance line $Z_{\mathrm{m}}{ }^{\prime}$. Figure 6 shows that quite a few points along the impedance line $Z_{\mathrm{m}}{ }^{\prime}$ are not located in the high-efficiency load impedance region of the Class-E PA. Furthermore, the impedance line $Z_{\mathrm{m}}$ ' does not pass through the centers of the efficiency and output power contour. Thus, the system efficiency and output power are not able to reach the theoretical maximum values. 


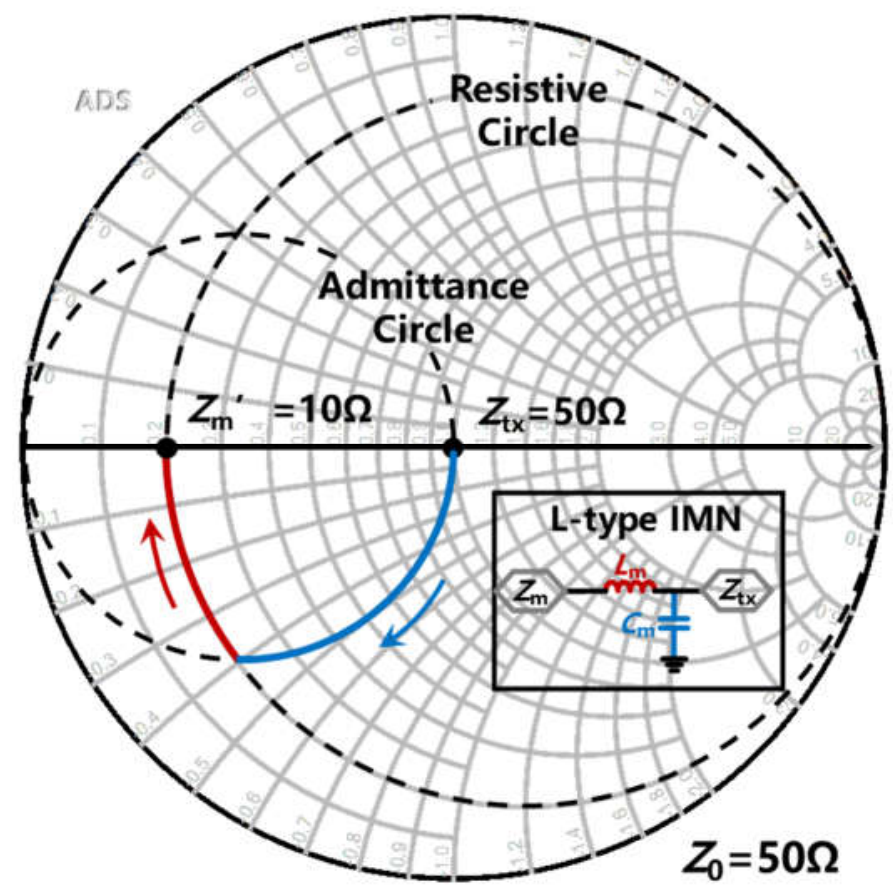

Figure 5. Impedance transformation with L-type IMN.

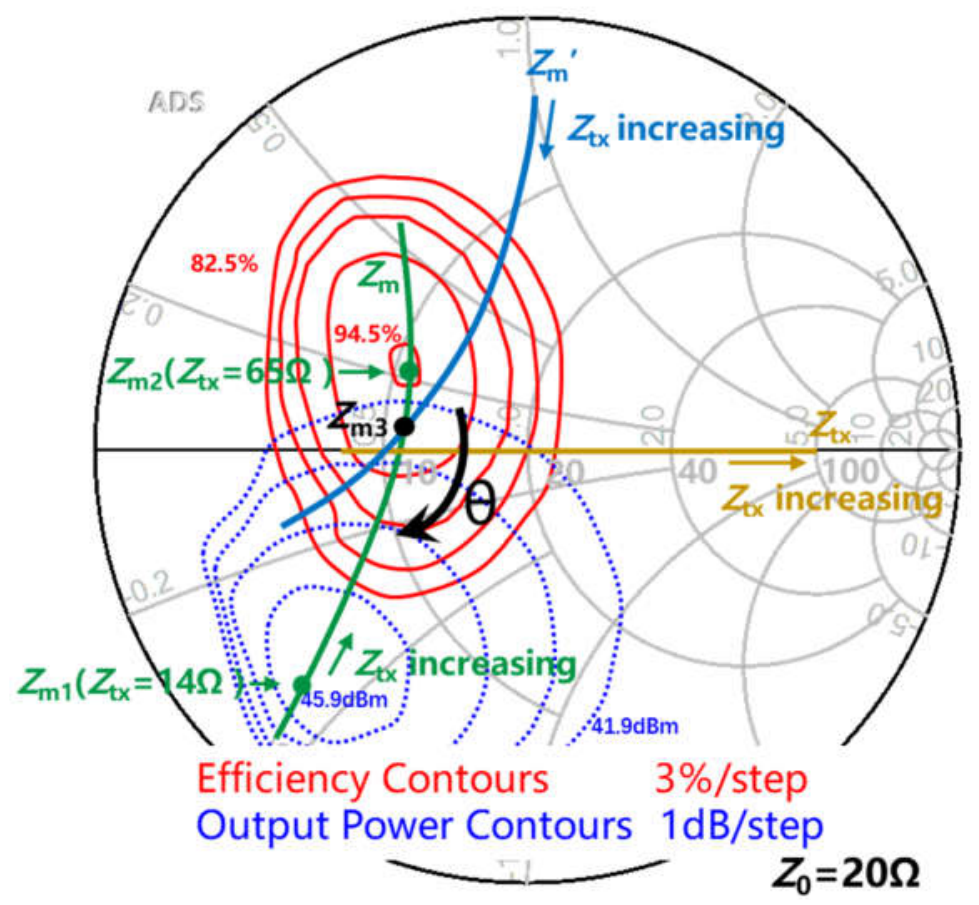

Figure 6. Efficiency and output power contours of Class-E PA.

The fixed L-type IMN is limited in its capability of impedance matching. Therefore, a symmetric $\pi$-type IMN is added to rotate the impedance line in the smith chart for better tuning. With carefully design, the impedance transformation characteristics of a symmetric $\pi$-type IMN could be similar to a transmission line, whose characteristic impedance is $Z_{c}$ [23]. It is known that the transmission line can rotate the impedance around the center of the smith chart and the rotation angle is related to the length of the transmission line. 
To rotate the $Z_{\mathrm{m}}$ ' to $Z_{\mathrm{m}}$ in the smith chart, the inductor $L_{\mathrm{t}}$ and the capacitor $C_{\mathrm{t}}$ of the symmetric $\pi$-type IMN are derived as

$$
\begin{gathered}
L_{\mathrm{t}}=\frac{Z_{\mathrm{c}} \sin (\theta / 2)}{\omega}, \\
C_{t}=\frac{1}{\omega Z_{\mathrm{c}}} \tan \frac{\theta}{4}
\end{gathered}
$$

where $Z_{c}$ is the center of rotation and $\theta$ is the rotation angle. In this design, set $Z_{c}=40 \Omega$, $\theta=155^{\circ}$. As shown in Figure $6, Z_{\mathrm{m} 3}$ (corresponding to $Z_{\mathrm{tx}}=40 \Omega$ ) is the center of rotation. The calculation results of $L_{\mathrm{t}}$ and $C_{\mathrm{t}}$ are presented in Table 1. Figure $4 \mathrm{c}$ shows a Class-E PA with an L-type and a symmetric $\pi$-type IMN. $C_{\mathrm{m}}$ and $C_{\mathrm{t}}$ can be united to one capacitor $C_{\mathrm{mt}}$. Thus, the L-type and the $\pi$-type IMN are combined to a double-L-type IMN. With the double-L-type IMN, the original impedance line $Z_{\mathrm{tx}}$ is transformed to a new impedance line $Z_{\mathrm{m}}$, which is shown in Figure $6 . Z_{\mathrm{m} 1}$ (corresponding to $Z_{\mathrm{tx}}=14 \Omega$ ) and $Z_{\mathrm{m} 2}$ (corresponding to $Z_{\mathrm{tx}}=65 \Omega$ ) are the maximum output power point and the maximum efficiency point of the Class-E PA, respectively. It can be seen from Figure 6 that most of the transformed impedance line $Z_{\mathrm{m}}$ locates within the high-efficiency working region of the Class-E PA and passes through the center of efficiency contour. Furthermore, the peak efficiency of the Class-E PA with double-L-type IMN is higher than the Class-E PA without IMN.

\begin{tabular}{|c|c|c|c|}
\hline & Symbol & Value & Description \\
\hline \multirow{7}{*}{ Class-E PA } & $L_{\mathrm{RFC}}$ & $47 \mathrm{uH}$ & RF choke inductor (MSS1583-473ME) \\
\hline & $r_{L R F C}$ & $0.05 \Omega$ & ESR of $L_{\mathrm{RFC}}$ \\
\hline & $C_{\mathrm{p}}$ & $431 \mathrm{pF}$ & Parallel capacitor \\
\hline & $C_{r}$ & $298 \mathrm{pF}$ & Resonant capacitor \\
\hline & $L r$ & $2.12 \mathrm{uH}$ & Resonant inductor \\
\hline & $S$ & - & GaN switch(TPH3206LD) \\
\hline & CPLD & - & $\begin{array}{l}\text { Control unit for generating driving signal } \\
\text { (EMP570T100C5N) }\end{array}$ \\
\hline \multirow{9}{*}{ Coupling Coils } & $L_{\mathrm{TX}}$ & $2.74 \mathrm{uH}$ & High-Q transmitting coil, $Q=695$ \\
\hline & $R_{\mathrm{TX}}$ & $0.17 \Omega$ & ESR of $L_{\mathrm{TX}}$ at $6.78 \mathrm{MHz}$ \\
\hline & $C_{\mathrm{TX}}$ & $201 \mathrm{pF}$ & Compensation capacitor of transmitting side \\
\hline & $L_{\mathrm{RX}}$ & $2.74 \mathrm{uH}$ & High-Q receiving coil, $\mathrm{Q}=695$ \\
\hline & $R_{\mathrm{RX}}$ & $0.17 \Omega$ & ESR of $L_{R X}$ at $6.78 \mathrm{MHz}$ \\
\hline & $C_{R X}$ & Calculated by (9) & Compensation capacitor of receiving side \\
\hline & $N_{\mathrm{TX}}, N_{\mathrm{RX}}$ & 2,2 & Turns of transmitting coil and receiving coil \\
\hline & $d_{\mathrm{TX}}, d_{\mathrm{RX}}$ & $3 \mathrm{~mm}, 3 \mathrm{~mm}$ & $\begin{array}{l}\text { Diameter of transmitting coil wire and } \\
\text { receiving coil wire }\end{array}$ \\
\hline & $r_{\mathrm{TX}}, r_{\mathrm{RX}}$ & $13 \mathrm{~cm}, 13 \mathrm{~cm}$ & Radius of transmitting coil and receiving coil \\
\hline \multirow{5}{*}{ Class-E Rectifier } & $L_{\mathrm{f}}$ & $47 \mathrm{uH}$ & Filter inductor (MSS1583-473ME) \\
\hline & $r_{L f}$ & $0.05 \Omega$ & ESR of $L_{\mathrm{f}}$ \\
\hline & $C_{\mathrm{f}}$ & $10 \mathrm{uF}$ & Filter capacitor \\
\hline & $C_{\mathrm{D}}$ & Calculated by (4) & Diode parallel capacitor \\
\hline & $D_{\mathrm{d}}$ & 0.5 & Duty cycle \\
\hline \multirow{4}{*}{ Double-L-type IMN } & $L_{\mathrm{m}}$ & $470 \mathrm{nH}$ & $\begin{array}{c}\text { High-Q inductors, } Q=200(2014 \text { VS-111ME, } \\
\text { 2014VS-251ME) }\end{array}$ \\
\hline & $C_{\mathrm{mt}}$ & $1409 \mathrm{pF}$ & / 1 \\
\hline & $L_{\mathrm{t}}$ & $916 \mathrm{nH}$ & $\begin{array}{l}\text { High-Q inductor, Q }=180 \text { (2929SQ-431_E, } \\
\text { 2929SQ-501_E) }\end{array}$ \\
\hline & $C_{\mathrm{t} 2}$ & $470 \mathrm{pF}$ & 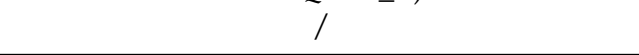 \\
\hline
\end{tabular}

Table 1. Design parameters of Class-E2-based WPT system. 


\subsection{Robustness of the Designed Class-E2-Based WPT System}

The performance of Class-E2-based WPT systems with/without a double-L-type WPT system are simulated with ADS. Pspice models of GaN switch TPH3206LD and diode STPSC 406 are used in the simulation. The DC power supply $V_{\mathrm{DC}}$ is set to $20 \mathrm{~V}$, and the operating frequency is set to $6.78 \mathrm{MHz}$. With (1)-(9), the parameters of the Class-E2based WPT system are determined and presented in Table 1. In order to ensure that the equivalent load impedance of the Class-E PA is a pure resistive load when the DC load is dynamically changed, the shunt capacitor $C_{D}$ and compensation capacitor $C_{R X}$ are required to be recalculated with (4) and (9).

The system efficiency and output power of the Class-E2-based WPT system are presented in Figure 7. Comparing Figures 7a and 7b, with the double-L-type IMN, the system efficiency shows significant improvement when the $Z_{\mathrm{tx}}$ value is larger, but decreases somewhat when the $Z_{\mathrm{tx}}$ value is small. In terms of output power, the maximum output power of the WPT system is improved with an IMN. In general, with the proposed double-L-type IMN, the Class-E2-based WPT system has strong robustness and can achieve high efficiency within a much wider range of coupling coefficients and load variations.

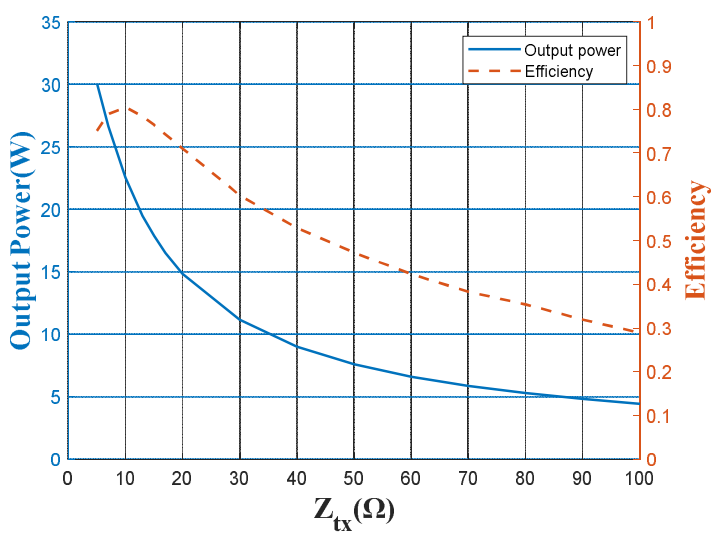

(a)

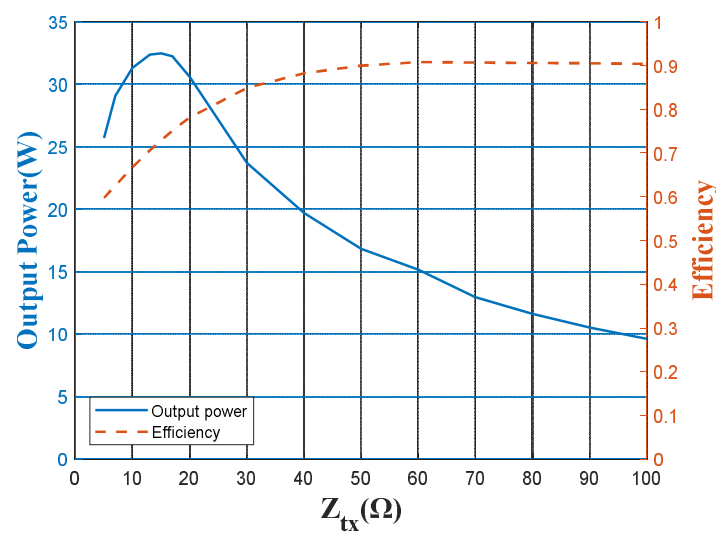

(b)

Figure 7. Output power and efficiency of Class-E2-based WPT system: (a) without double-L-type IMN; (b) with double-Ltype IMN.

\section{Experimental Verification}

To verify the proposed impedance matching method, a Class-E2-based WPT system was fabricated, as shown in Figure 8. In Figure 8, different parts of the WPT system, including the Class-E PA, double-L-type IMN, coupling coils, Class-E rectifier, and DC load, are connected to each other with SMA ports. SMA ports are appropriate for highfrequency systems and are quite convenient to assemble and disassemble. Experimental PCBs are shown in Figure 9, which were fabricated on a 1.6mm FR-4 substrate. The design parameters and component descriptions of the Class-E PA, coupling coils, Class-E rectifier, and double-L-type IMN are shown in Table 1. In practice, the value of $C_{\mathrm{p}}$ is smaller than the theoretical value presented in Table 1 because the parasitic output capacitor of the $\mathrm{GaN}$ switch is around $100 \mathrm{pF}$. The parasitic parameters, such as parasitic resistance of the inductors and on-resistance of the switch, have an influence on system efficiency. To improve system efficiency, high-Q inductors with small parasitic resistance are preferred. Furthermore, with temperature increases, the parasitic resistance of the inductors and onresistance of the switch increase, which lead to more power loss. Therefore, the PCB layout need to be carefully designed for heat dissipation. In terms of the Class-E rectifier, note that the shunt capacitor of diode $C_{\mathrm{D}}$ and compensation capacitor of receiving side $C_{\mathrm{RX}}$ are required to be recalculated when the DC load $R_{\mathrm{L}}$ is changed. Furthermore, in practice, the value of $C_{\mathrm{D}}$ is smaller than the calculated value presented in Table 1 because the parasitic junction capacitor of the diode is around 40pF. A double-L-type IMN is added between 
the Class-E PA and transmitting coil, which is employed to maintain the high efficiency of the Class-E PA under a wider range of coupling coefficients and load variations. The load impedance of the Class-E PA can be transformed into a high-efficiency working region with a double-L-type IMN. Two Class-E2-based WPT systems, i.e., a system with double-Ltype IMN and system without a double-L-type IMN, were fabricated and compared. The experimental parameters are presented in Table 2.

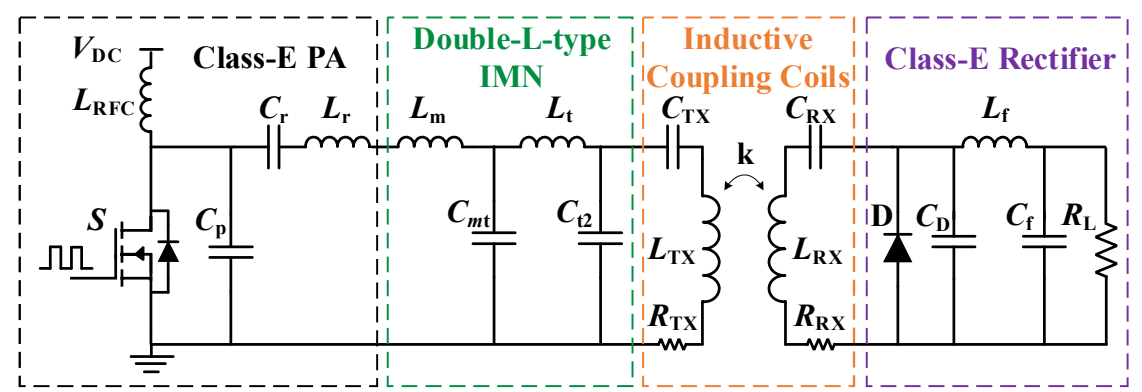

(a)

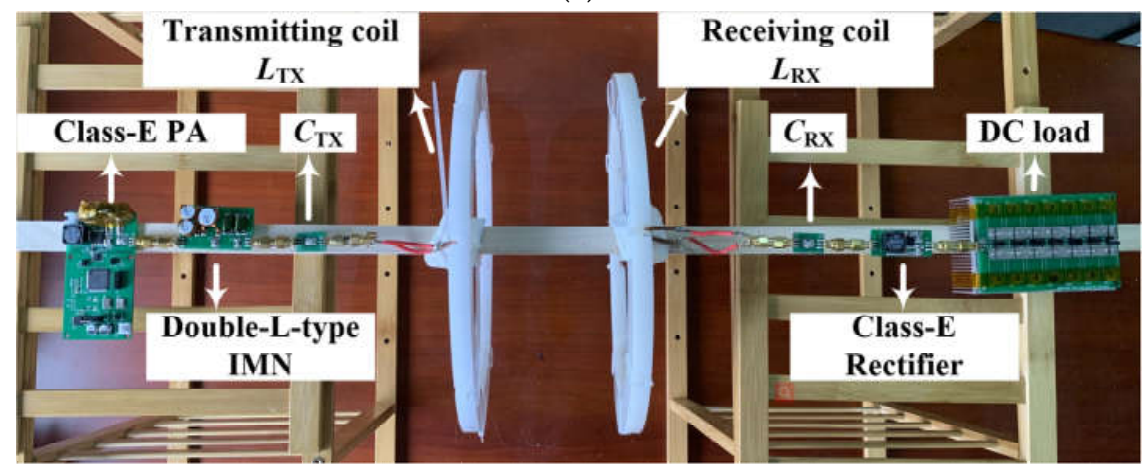

(b)

Figure 8. Experimental circuit of proposed Class-E2-based WPT system: (a) schematic; (b) photograph.

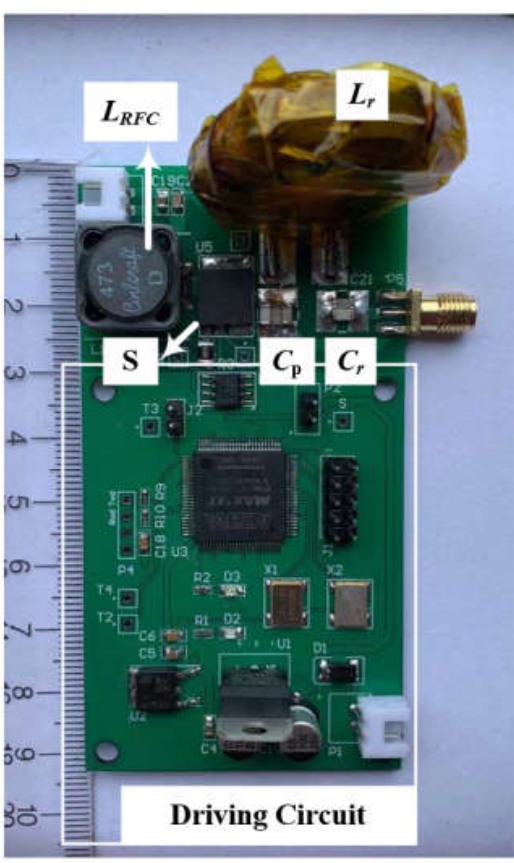

(a)

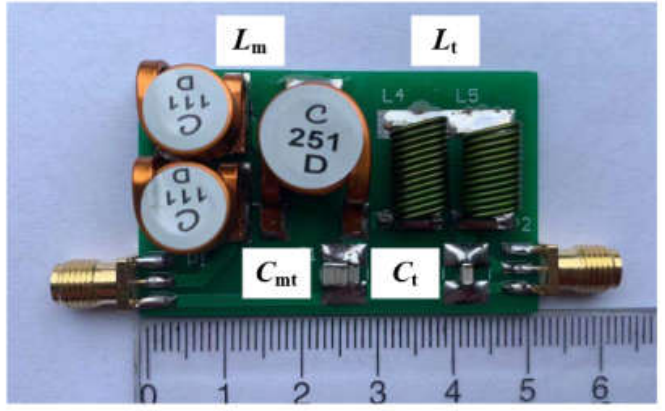

(b)

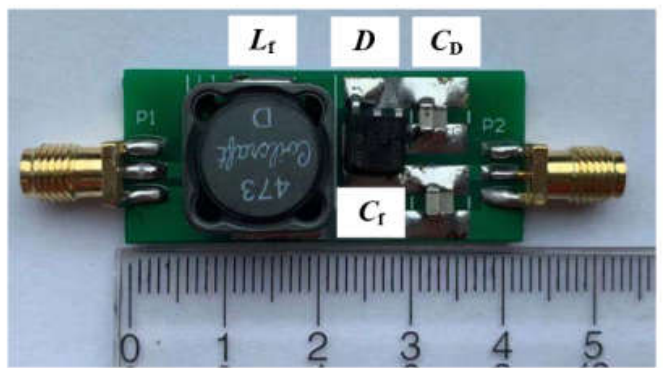

(c)

Figure 9. Experimental PCBs: (a) Class-E PA; (b) double-L-type IMN; (c) Class-E Rectifier. 
Table 2. Experimental parameters.

\begin{tabular}{ccc}
\hline Coil Distance $\boldsymbol{D}$ & Coupling Coefficient $\boldsymbol{k}$ & DC Load $\boldsymbol{R}_{\mathrm{L}}$ \\
\hline $5 \sim 25 \mathrm{~cm}$ & $0.027 \sim 0.267$ & $5 \sim 30 \Omega$ \\
\hline
\end{tabular}

Figure 10 shows the drain voltage $V_{\text {DS }}$ of the Class-E PAs with/without a double-Ltype impedance IMN when the coil distance and DC load are dynamically changed. As shown in Figure 10a,c,e, it is obvious that the Class-E PA without IMN is not operated in ZVS and ZDS mode when the coil distance and load deviate from their optimum values. In the cases presented in Figure $10 \mathrm{a}, \mathrm{c}$, the drain voltage $V_{\mathrm{DS}}$ remains high when the state of the switch becomes ON, namely with hard-switching $\mathrm{ON}$, thus the switching process produces large amounts of waste and noise. The power losses of a hard-switching system are very large, especially in this high-frequency WPT system, which leads to a sharp decline in system efficiency. As shown in Figure 10b,d,f, in most cases of a WPT system with the double-L-type IMN, the drain voltage $V_{\mathrm{DS}}$ is almost zero when the state of the switch becomes $\mathrm{ON}$, namely with soft-switching $\mathrm{ON}$, thus the power losses caused by the switching process are significantly reduced. The duty cycle of the switch is designed to be $50 \%$ in the system. However, in Figure 10d-f, there are cases of duty cycles that are smaller than $50 \%$, which are caused by the mismatch of Class-E PA load impedance. In these cases, the drain voltage is clamped by the parasitic diode of the switch when it is going to be a negative value. This process causes additional power losses in the parasitic diode and leads to a decline in system efficiency.

The experimental results for the system efficiency of a Class-E2-based WPT system with/without a double-L-type IMN are shown in Figure 11. The efficiency of the Class-E2based WPT system without an IMN drops rapidly when the coil distance and load deviate from their optimum values. As shown in Figure 11a, the WPT system can only achieve high efficiency within a narrow-range of coil distance and load variation. Furthermore, the lowest system efficiency is under $15 \%$. In terms of system efficiency, the Class-E2-based WPT system with the double-L-type IMN shows an obvious advantage over the system without a double-L-type IMN. Comparing Figures 11a and 11b, with a double-L-type IMN, the Class-E2-based WPT system is able to maintain high efficiency when the coil distance and load change over a much wider range. 


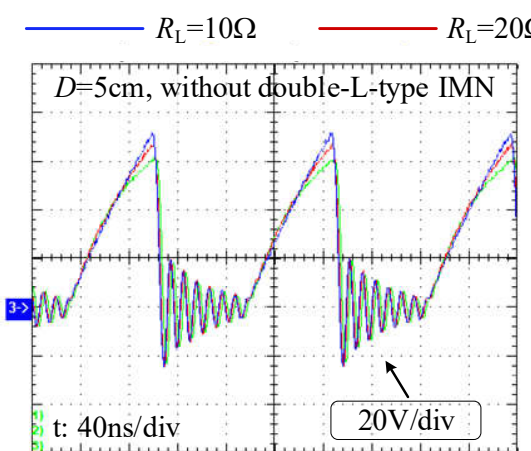

(a)

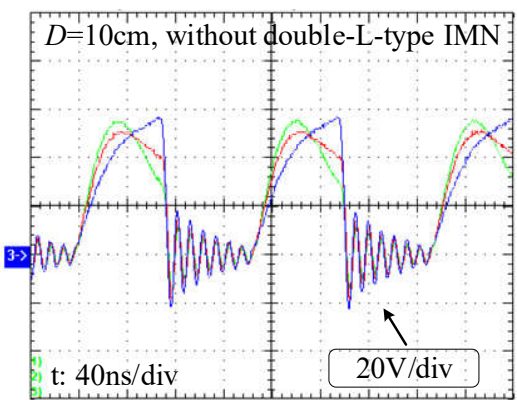

(c)

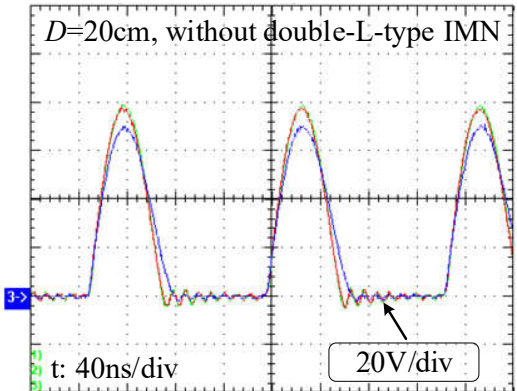

(e)

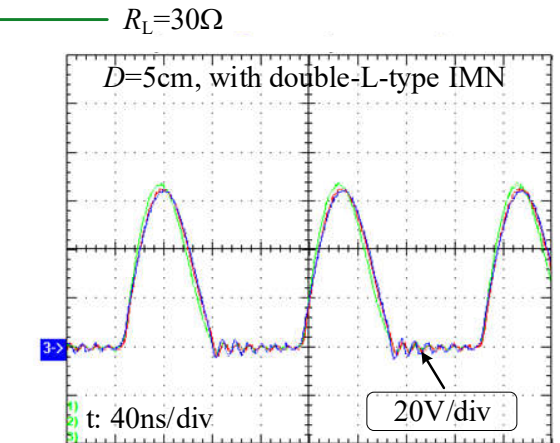

(b)

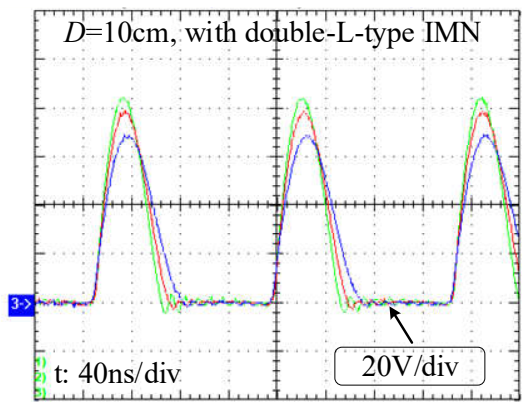

(d)

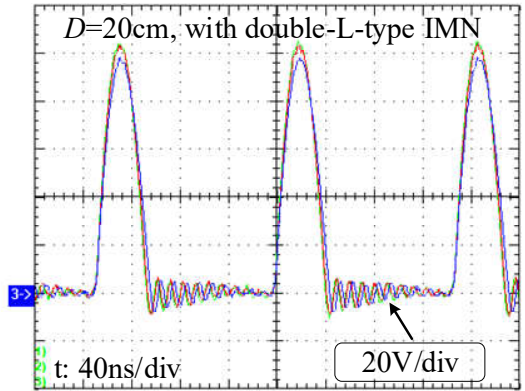

(f)

Figure 10. Drain voltage $V_{\mathrm{DS}}$ of Class-E PA without/with double-L-type IMN under various coil distances $\mathrm{D}$ and loads $R_{\mathrm{L}}:(\mathbf{a}, \mathbf{b}) \mathrm{D}=5 \mathrm{~cm} ;(\mathbf{c}, \mathbf{d}) \mathrm{D}=10 \mathrm{~cm} ;(\mathbf{e}, \mathbf{f}) \mathrm{D}=20 \mathrm{~cm}$.

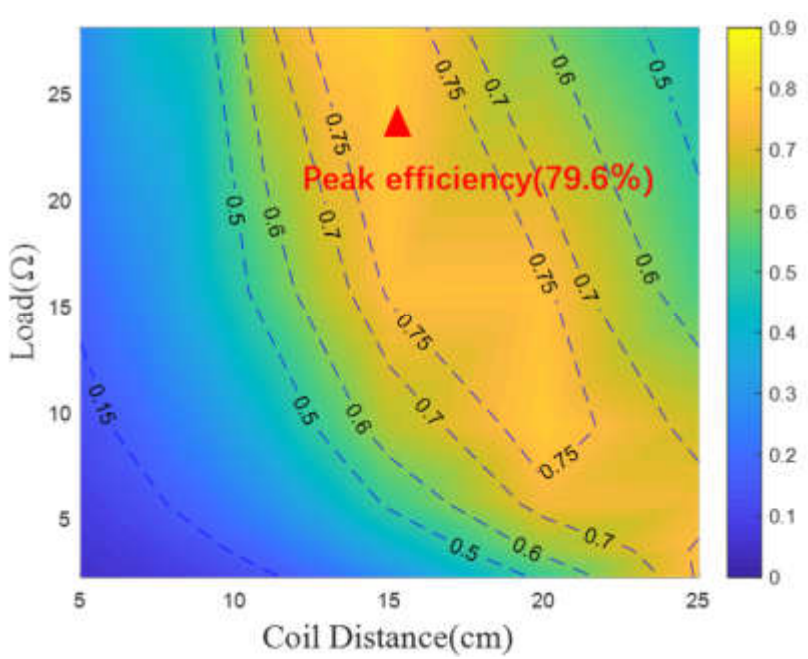

(a)

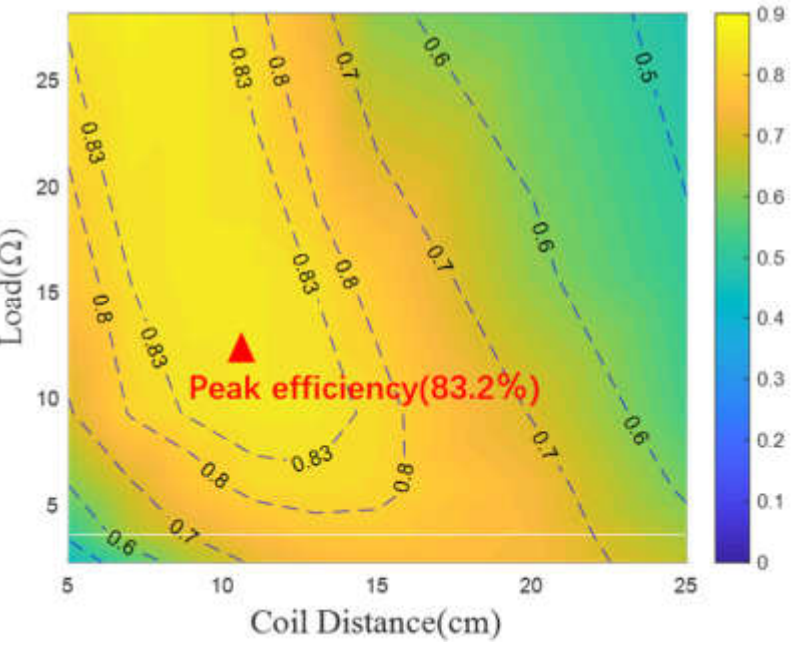

(b)

Figure 11. Efficiency of Class-E PA with coil distance and load variation: (a) without double-L-type IMN; (b) with double-L-type IMN. 


\section{Conclusions}

A Class-E2 DC-DC converter, featuring high efficiency and a simple structure, is attractive for a megahertz WPT system. However, system efficiency decreases rapidly when the coupling coefficient and load deviate from their optimum values, which is mainly caused by the mismatch of Class-E PA load impedance. In this paper, an impedance matching method for a $6.78 \mathrm{MHz}$ Class-E2-based WPT system was proposed. The purpose was to improve system efficiency when the coil coupling coefficient and load varies over a wider range. The load-pull technique was employed to identify the high-efficiency load impedance region of the Class-E PA. A double-L-type IMN was proposed to achieve fine impedance transformations. High-Q coils and inductors were employed to reduce parasitic power losses. As shown in Figure 12, the efficiency of the system with a double-L-type IMN (DC load of $10 \Omega$ ) was compared with the existing technologies, demonstrating the advantages of the static double-L-type IMN in improving system efficiency within a certain transfer distance. The experimental results show that the lowest system efficiency of a conventional Class-E2-based WPT system is under 15\% when the equivalent load impedance of the Class-E PA deviates too far from its optimum value. Conversely, with a double-L-type IMN, system efficiency is over $55 \%$ for a wider range of coil coupling coefficient and load variations, and peak system efficiency reaches $83.2 \%$ with $13.7 \mathrm{~W}$ output power. Thus, the impedance matching method and design procedure proposed in this paper were validated and could provide a practical solution for building a highefficiency WPT system with strong robustness.

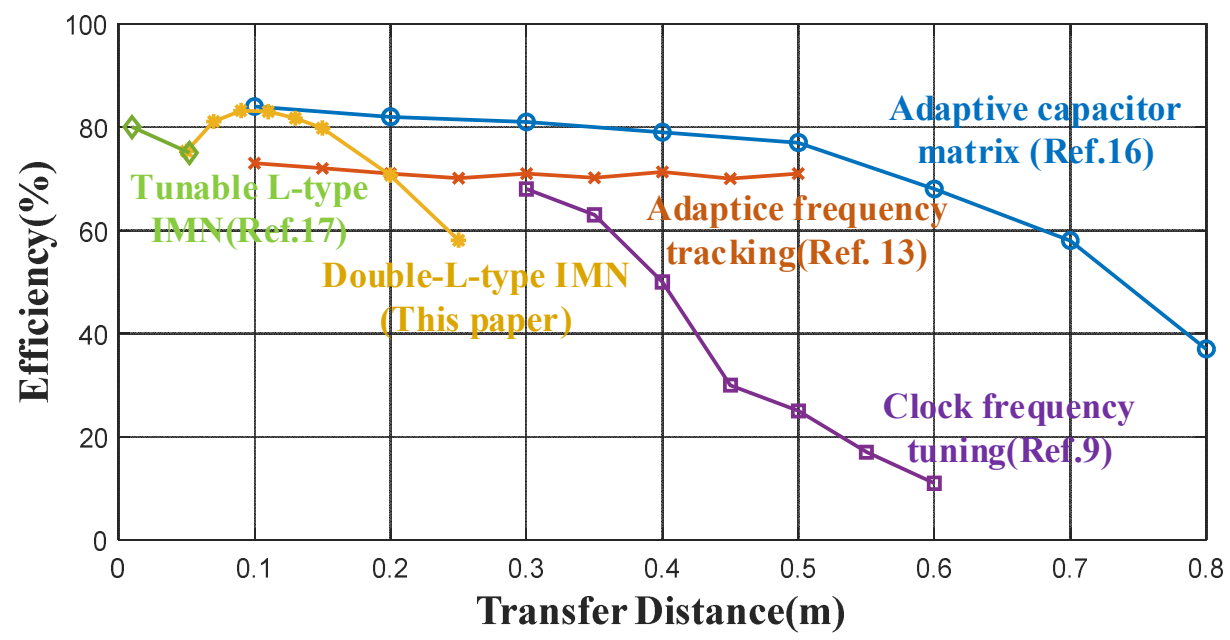

Figure 12. Efficiency for the system with double-L-type IMN and comparison with existing technologies (the data are from graph in the references).

Author Contributions: Conceptualization, Y.Z. and J.W.; data curation, Y.Z.; software, S.L.; validation, Y.Z. and Y.F.; formal analysis, Y.Z.; investigation, Y.Z. and Y.F.; writing-original draft preparation, Y.Z.; writing - review and editing, Y.Z., Y.F. and J.W.; visualization, S.L.; supervision, J.W., and X.H.; funding acquisition, X.H. All authors have read and agreed to the published version of the manuscript.

Funding: This research was funded by the National Natural Science Foundation of China, under Grant 51977189, U1834205.

Institutional Review Board Statement: Not applicable.

Informed Consent Statement: Not applicable.

Data Availability Statement: Not applicable.

Conflicts of Interest: The authors declare no conflict of interest. 


\section{References}

1. Kurs, A.; Karalis, A.; Moffatt, R.; Joannopoulos, J.D.; Fisher, P.; Soljacic, M. Wireless power transfer via strongly coupled magnetic resonances. Science 2007, 317, 83-86. [CrossRef] [PubMed]

2. Hui, S.Y.R.; Zhong, W.; Lee, C.K. A Critical Review of Recent Progress in Mid-Range Wireless Power Transfer. IEEE Trans. Power Electron. 2014, 29, 4500-4511. [CrossRef]

3. Yin, H.; Fu, M.; Liu, M.; Song, J.; Ma, C. Autonomous Power Control in a Reconfigurable 6.78-MHz Multiple-Receiver Wireless Charging System. IEEE Trans. Ind. Electron. 2018, 65, 6177-6187. [CrossRef]

4. Cheng, C.; Lu, F.; Zhou, Z.; Li, W.; Zhu, C.; Zhang, H.; Deng, Z.; Chen, X.; Mi, C.C. Load-Independent Wireless Power Transfer System for Multiple Loads Over a Long Distance. IEEE Trans. Power Electron. 2019, 34, 9279-9288. [CrossRef]

5. Sayed, S.; Salahuddin, S.; Yablonovitch, E. Spin-orbit torque rectifier for weak RF energy harvesting. Appl. Phys. Lett. 2021, 118, 052408. [CrossRef]

6. Sharma, R.; Mishra, R.; Ngo, T.; Guo, Y.X.; Fukami, S.; Sato, H.; Ohno, H.; Yang, H. Electrically connected spin-torque oscillators array for $2.4 \mathrm{GHz}$ WiFi band transmission and energy harvesting. Nat. Commun. 2021, 12, 2924. [CrossRef] [PubMed]

7. Fang, B.; Carpentieri, M.; Louis, S.; Tiberkevich, V.; Slavin, A.; Krivorotov, I.N.; Tomasello, R.; Giordano, A.; Jiang, H.; Cai, J.; et al. Experimental Demonstration of Spintronic Broadband Microwave Detectors and Their Capability for Powering Nanodevices. Phys. Rev. Appl. 2019, 11, 014022. [CrossRef]

8. Nagashima, T.; Wei, X.; Bou, E.; Alarcon, E.; Kazimierczuk, M.K.; Sekiya, H. Analysis and Design of Loosely Inductive Coupled Wireless Power Transfer System Based on Class-E2 DC-DC Converter for Efficiency Enhancement. IEEE Trans. Circuits Syst. I Regul. Pap. 2015, 62, 2781-2791. [CrossRef]

9. Tomoharu Nagashima, K.I.; Wei, X.; Bou, E.; Alarc'on, E.; Kazimierczuk, M.K.; Sekiya, H. Analytical design procedure for resonant inductively coupled wireless power transfer system with class-E2 DC-DC converter. In Proceedings of the IEEE International Symposium on Circuits and Systems (ISCAS), Melbourne, Australia, 1-5 June 2014; pp. 113-116.

10. Kazimierczuk, M.K.; Jozwik, J. DC/DC converter with class E zero-voltage-switching inverter and class E zero-current-switching rectifier. IEEE Trans. Circuits Syst. 1989, 36, 1485-1488. [CrossRef]

11. Liu, S.K.; Liu, M.; Fu, M.F.; Ma, C.B.; Zhu, X.E. A High-Efficiency Class-E Power Amplifier with Wide-Range Load in WPT Systems. In Proceedings of the 2015 IEEE Wireless Power Transfer Conference (Wptc), Boulder, CO, USA, $13-15$ May 2015.

12. Pinuela, M.; Yates, D.C.; Lucyszyn, S.; Mitcheson, P.D. Maximizing DC-to-Load Efficiency for Inductive Power Transfer. IEEE Trans. Power Electron. 2013, 28, 2437-2447. [CrossRef]

13. Aldhaher, S.; Luk, P.C.-K.; Whidborne, J.F. Electronic Tuning of Misaligned Coils in Wireless Power Transfer Systems. IEEE Trans. Power Electron. 2014, 29, 5975-5982. [CrossRef]

14. Liu, M.; Fu, M.F.; Ma, C.B. A Compact Class E Rectifier for Megahertz Wireless Power Transfer. In Proceedings of the 2015 IEEE Pels Workshop on Emerging Technologies-Wireless Power (Wow), Daejeon, Korea, 5-6 June 2015.

15. Rybicki, K.; Wojciechowski, R.M. Analysis and design of a class E current-driven rectifier for $1 \mathrm{MHz}$ wireless power transfer system. J. Electr. Eng. 2019, 70, 58-63. [CrossRef]

16. Kim, N.Y. Adaptive Magnetic Resonance Wireless Power Transfer System with Optimum frequency and Power-Leve Tracking for maintaining highly efficient. In Proceedings of the International Conference on Artificial Intelligence in Information and Communication (ICAIIC), Okinawa, Japan, 11-13 February 2019; pp. 543-547.

17. Assawaworrarit, S.; Fan, S. Robust and efficient wireless power transfer using a switch-mode implementation of a nonlinear parity-time symmetric circuit. Nat. Electron. 2020, 3, 273-279. [CrossRef]

18. Sample, A.P.; Waters, B.H.; Wisdom, S.T.; Smith, J.R. Enabling Seamless Wireless Power Delivery in Dynamic Environments. Proc. IEEE 2013, 101, 1343-1358. [CrossRef]

19. Lim, Y.; Tang, H.; Lim, S.; Park, J. An Adaptive Impedance-Matching Network Based on a Novel Capacitor Matrix for Wireless Power Transfer. IEEE Trans. Power Electron. 2014, 29, 4403-4413. [CrossRef]

20. Liu, S.; Liu, M.; Han, S.; Zhu, X.; Ma, C. Tunable Class E2 DC-DC Converter with High Efficiency and Stable Output Power for 6.78-MHz Wireless Power Transfer. IEEE Trans. Power Electron. 2018, 33, 6877-6886. [CrossRef]

21. Kazimierczuk, M.K.; Puczko, K. Exact Analysis of Class-E Tuned Power-Amplifier at Any Q and Switch Duty Cycle. IEEE Trans. Circuits Syst. 1987, 34, 149-159. [CrossRef]

22. Kazimierczuk, M.K.; Jozwik, J. Resonant DC/DC converter with class-E inverter and class-E rectifier. IEEE Trans. Ind. Electron. 1989, 36, 468-478. [CrossRef]

23. Symmetrical pi Network in Network Analysis. Available online: https://www.eeeguide.com/symmetrical-pi-network-innetwork-analysis / (accessed on 26 June 2021). 